\title{
Effects of Nanoparticle Size on Catalytic and Photocatalytic Activity of Carbon Nanotubes-Titanium Dioxide Composites
}

\section{Firas H Abdulrazzak and Falah H Hussein*}

Chemistry Department, College of Science, University of Babylon, 51002 Hilla, Iraq

Continuous changes in production techniques of composites have attracted the attention of researchers in the various branches of science, starting from academic research and ending in engineered materials. These techniques aim to preserve their beneficial properties and try to increase their efficiency with the introduction of new standards to this component which may not be already owned or efficient in a few capacities and are intended to be introduced to the composites [1]. One of the most important properties is produces nanomaterials along with the improvement of its physiochemical properties, due to the unique importance in the technology of its applications [2]. $\mathrm{TiO}_{2}$ is a common semiconductor material that is used in this way due to many causes such as it being inexpensive, and nontoxic [3], and its relatively high reactivity and chemical stability under ultraviolet light [4]. Photocatalytic reactions at the surface of titanium dioxide have been used in many applications such as environmental cleaning for selfcleaning material on the surface coating of, glasses, and windows [5]. This new carbon-material, consists of Carbon nanotube CNTs, which appeared to have become a reality for science thanks to Iijima [6], and which was a challenge and temptation at the same time due to it being unknown to some extent, it's amazing physiochemical properties [7], and the variety of types of single-walled carbon nanotubes (SWNTs), few-walled carbon nanotubes (FWCNTs), and multi-walled carbon nanotubes (MWNTs).Many attempts brought together a, high surface area, fascinating electronic, chemical and mechanical properties for CNTs [8] with a low surface area for $\mathrm{TiO}_{2}$, in addition to the properties mentioned above. The addition of CNTs to $\mathrm{TiO}_{2}$ created new properties and structural stability, which improved their activities compared to the pristine $\mathrm{TiO}_{2}$ particle size, thus representing the key to understanding or at least finding a suitable proposal for this behavior. Raman spectroscopy [9] and XRD represent powerful methods for the investigation of the particle size effect in the activities of these nano- materials. The relations between the surface structure and particle size were translated into creating new bounds between them. Two types of binary composite were synthesized by using MWNTs, and SWNTs, which were purchased from (Aldrich). According to the product specifications, the two compounds were fabricated by the chemical vapor deposition method. SWNT constancies of more than $90 \%$ carbon included $77 \%$ SWNTs, with a diameter of $0.7-1.1 \mathrm{~nm}$. The MWNT 95\% carbon nanotubes with a mode diameter of 5.5, and the $\mathrm{TiO}_{2}$ sample were purchased from Degussa, Germany ( $\left.\mathrm{TiO}_{2}-\mathrm{P} 25\right) .0 .5 \%$ $\mathrm{CNT} / \mathrm{TiO}_{2}$ was prepared by an impregnation method. First, SWNTs, or MWNTs were treated with a mixture of $\mathrm{HNO}_{3} / \mathrm{H}_{2} \mathrm{SO}_{4}$ acid (1/3) in an ultrasonic water bath for $7 \mathrm{~h}$ to make activation for the surfaces [10]. After that $1 \mathrm{~g}$ of the $\mathrm{TiO}_{2}$ photocatalyst was suspended in an ultrasonic water bath in $100 \mathrm{ml}$ of distilled water for $30 \mathrm{~min}$. which contained the desired percentage weight of CNTs $(0.5 \%)$. The mixed suspension was filtered by using a vacuum evaporator (Rota vapor re121 BUSHI 461 water Bath) at $45^{\circ} \mathrm{C}$ to accelerate the evaporation of the water. After the water had evaporated, the composite was dried overnight in an oven at $104^{\circ} \mathrm{C}$. The samples were characterized using, Brunauer, Emmett and Teller BET to measure the specific surface area of the materials, the XRD pattern, and Raman spectroscopy. The effect of the existence of $0.5 \%$ CNTs a summarized in (Table 1 ) by using the full-width at halfmaximum (FWHM) of the given bands, which were found by using the origin program8.
As shown in (Figure 1), the Raman spectra of the pristine $\mathrm{TiO}_{2}$, $0.5 \% \mathrm{SWNT} / \mathrm{TiO}_{2}$, and $0.5 \% \mathrm{MWNT} / \mathrm{TiO}_{2}$, represented by the five Raman-active modes of the anatase phase with symmetries of $2 \mathrm{E}_{\mathrm{g}}, \mathrm{A}_{\mathrm{lg}}$, $\mathrm{B}_{1 \mathrm{~g}}$, and $\mathrm{E}_{\mathrm{g}}$, at $145.1,198.0,398.0,515.5$ and $638.5 \mathrm{~cm}^{-1}$ respectively, and $\mathrm{E}_{\mathrm{g}}$ with a very small intensity at $445 \mathrm{~cm}^{-1}$. $\mathrm{TiO}_{2}-\mathrm{P} 25$, as a mixture of anatase and rutile, has five Raman peaks (at 145.1, 198, 398, 516.5 and $6398.5 \mathrm{~cm}^{-1}$ ) corresponding to the anatase, but just one peak, at $445 \mathrm{~cm}^{-1}$, corresponding to the rutile [11]. Comparing $\mathrm{TiO}_{2}$ with the synthesized materials shows: $\mathrm{i}-\mathrm{FWHM}$ of the $\mathrm{TiO}_{2}$, increased with the existence of SWNTs and MWNTs, which increased within the SWNTs more than the MWNTs, ii- the shift in wavenumber for high values within the SWNTs and MWNTs, which showed more deviation with the SWNTs. As shown in (Figure 2), the low ratios of CNTs in the composites did not cause large or clear changes in the crystallography of the $\mathrm{TiO}_{2}$ which may be related to covering the composites by the much more intense peak for the large ratio of the $\mathrm{TiO}_{2}$, however the effect of CNTs was limited to the small change in the width of the peaks with a shift towards a higher $2 \theta$, which is summarized in (Table 2), in addition to a decrease with particle size which can be found from the Debye-Scherrer equation $(\mathrm{d}=\mathrm{K} \lambda / \beta \cos \theta)[12]$. The CNTs showed two characteristic peaks at $2 \theta=25.9^{\circ}$ and $43.2^{\circ}$, which can be attributed to the diffraction from the $\mathrm{C}(100)$ and $\mathrm{C}(002)$ planes of the carbon nanotube; the second peak was more intense in the MWNTs than the SWNTs [13], which may explain the value of the surface area for $0.5 \% \mathrm{MWNT} /$ $\mathrm{TiO}_{2}\left(64 \mathrm{~m}^{2} / \mathrm{g}\right)$, which was more than $0.5 \% \mathrm{SWNT} / \mathrm{TiO}_{2}\left(54 \mathrm{~m}^{2} / \mathrm{g}\right)$ and $\mathrm{TiO}_{2}\left(51 \mathrm{~m}^{2} / \mathrm{g}\right)$. The test of the activities was done by using Cobalamin $\left(\mathrm{C}_{63} \mathrm{H}_{88} \mathrm{CoN}_{14} \mathrm{P}\right)$, which is vitamin $\mathrm{B} 12$, as a complex compound of an organometallic species with a cobalt atom that is distinguished in a Corrine ring [14] which at the same time may give the explanation for the adsorption properties in the following sequences: $0.5 \% \mathrm{MWNT} /$ $\mathrm{TiO}_{2}>0.5 \% \mathrm{SWNT} / \mathrm{TiO}_{2}>\mathrm{TiO}_{2}$.

\begin{tabular}{|c|c|c|c|c|c|}
\hline Sample & $E_{g}$ & $E_{g}$ & $B_{1 g}$ & $A_{1 g}$ & $E_{g}$ \\
\hline $\mathrm{TiO}_{2}$ & 145.1(11.38) & 198.0(5.69) & $398.0(7.85)$ & $515.5(7.85)$ & $638.5(9.48)$ \\
\hline $0.5 \%$ SWNT $/ \mathrm{TiO}_{2}$ & $147.0(14.46)$ & 201.3(6.32) & $399.5(9.03)$ & $517.0(9.03)$ & $639.0(10.48)$ \\
\hline $\begin{array}{c}0.5 \% \mathrm{MWNT}^{\prime} \\
\mathrm{TiO}_{2}\end{array}$ & $145.8(13.84)$ & 198.2(5.85) & $398.0(7.89)$ & $515.5(7.89)$ & $639.0(11.07)$ \\
\hline \multicolumn{6}{|c|}{ Table 1: The effect of the existence of $0.5 \%$ CNTs } \\
\hline Samples & $\operatorname{BET}\left(\mathrm{m}^{2} / \mathrm{g}\right)$ & \multicolumn{2}{|c|}{ Particle size $(\mathrm{nm})$} & $C_{0 p p m}$ & $\mathbf{k}\left(\mathbf{s}^{-1}\right)$ \\
\hline $\mathrm{TiO}_{2}$ & 51 & \multicolumn{2}{|c|}{23.09} & $\approx 40$ & 0.0648 \\
\hline $0.5 \%$ SWNT /TiC & 56 & \multicolumn{2}{|c|}{15.41} & 36.80 & 0.0769 \\
\hline $0.5 \%$ MWNT /TiC & 64 & \multicolumn{2}{|c|}{20.84} & 31.20 & 0.0743 \\
\hline
\end{tabular}

Table 2: The effect of CNTs with a shift towards a higher $2 \theta$

*Corresponding author: Falah $\mathrm{H}$ Hussein, Department of Chemistry, College of Science, University of Babylon, 51002 Hilla, Iraq, Tel: 00964-780-1006256; E-mail: abohasan_hilla@yahoo.com

Received February 24, 2015; Accepted February 25, 2015; Published February 28, 2015

Citation: Abdulrazzak FH, Hussein FH (2015) Effects of Nanoparticle Size on Catalytic and Photocatalytic Activity of Carbon Nanotubes-Titanium Dioxide Composites. J Environ Anal Chem 2: e110. doi:10.41722380-2391.1000e110

Copyright: () 2015 Abdulrazzak FH, et al. This is an open-access article distributed under the terms of the Creative Commons Attribution License, which permits unrestricted use, distribution, and reproduction in any medium, provided the original author and source are credited. 


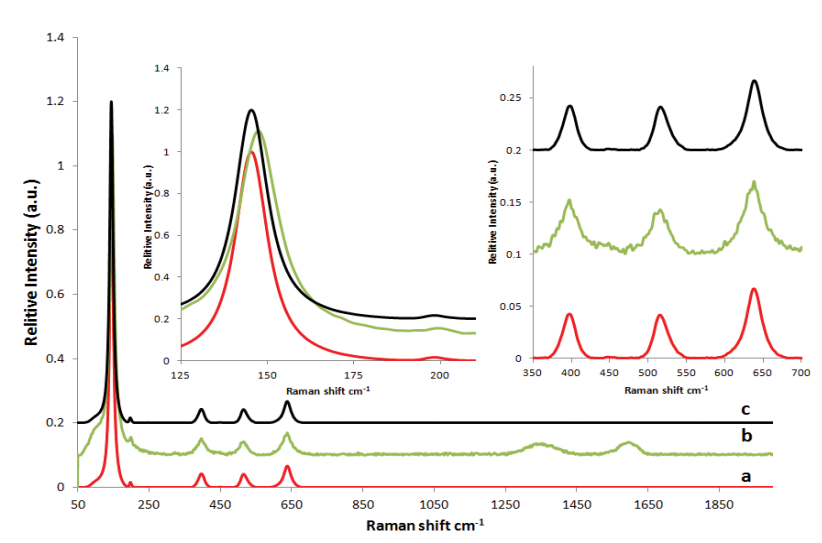

Figure 1: Raman spectra of (a) $\mathrm{TiO}_{2}$, (b) $0.5 \% \mathrm{SWNT} / \mathrm{TiO}_{2}$, and (c) $0.5 \%$ $\mathrm{MWNT} / \mathrm{TiO}_{2}$

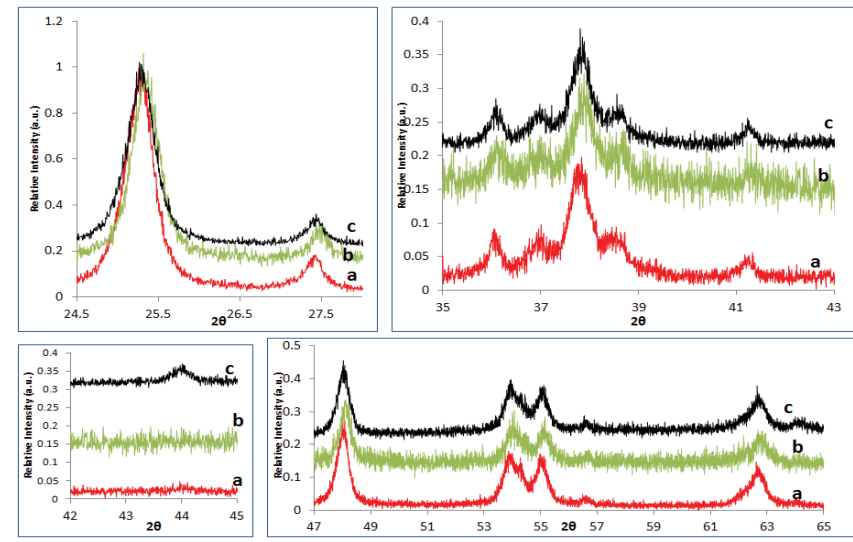

Figure 2: XRD patterns of (a) $\mathrm{TiO}_{2}$, (b) $0.5 \% \mathrm{SWNT} / \mathrm{TiO}_{2}$, and (c) $0.5 \% \mathrm{MWNT} /$ $\mathrm{TiO}_{2}$

This refers to the homogenous distribution of SWNTs in the composite which is more than MWNTs, thus the sequences of photocatalytic degradation are: $0.5 \% \mathrm{SWNT} / \mathrm{TiO}_{2}>0.5 \% \mathrm{MWNT} /$ $\mathrm{TiO}_{2}>\mathrm{TiO}_{2}$.

There is a shift in the Raman bands towards a higher wavenumber with a decrease in the intensities of the peak with a reduction the value of the particle size on the nanoparticale scale $[9,15]$. The change in intensity and brooding and the effects of the SWNTs more than the MWNTs are as a result of the lower densities of the SWNTs [16], which makes the distribution of SWNTs with particles of titanium dioxide more regular and homogenous than MWNTs, due to the abilities of SWNTs and MWNTs to distribute and reduce the agglomerates of the $\mathrm{TiO}_{2}$ particles.
In conclusion, titanium dioxide as a semiconductor can improve the activities by adding different types of CNTs, which could increase the adsorption and photoactivity for $\mathrm{TiO}_{2}$. The Raman spectrum and $\mathrm{XRD}$ with the measurement of the surface area represent the ideal ways for enplaning' the change in the activities of $\mathrm{TiO}_{2}$.

\section{References}

1. Adriana Z (2008) Doped-TiO2: A Review, Recent Patents on Engineering 2: 157-164.

2. Weller H (1993) Colloidal Semiconductor Q-Particles: Chemistry in the Transition Region between Solid State and Molecules. Chem.Int. Ed. Engl 32: 41-53.

3. Bonetta S, Bonetta S, Motta F, Strini A, Carraro E (2013) Photocatalytic bacterial inactivation by TiO2-coated surfaces. AMB Express 3: 59.

4. Chaweng KC, Hayata $\mathrm{Y}$ (2008) Development of $\mathrm{TiO}_{2}$ powder-coated food packaging film and its ability to inactivate Escherichia coli in vitro and in actual tests. Int J Food Microbiol 123:288-292.

5. Fujishima X, Zhang CR (2006) Titanium dioxide photocatalysis: Present situation and future approaches. Comptes Rendus Chimie 9: 750-760.

6. lijima S (1991) Helical Microtubules of Graphitic Carbon. Nature 354: 56-58

7. Kenan S, Yiying Z, Jiangsha M, Emily CG, Navid T, et al. (2013) Structural polymer-based carbon nanotube composite fibers: understanding the processing-structure-performance relationship. Materials 6: 2543-2577.

8. Avramov PV, Yakobson BI, and Scuseria GE (2004) Effect of Carbon Network Defects on the Electronic Structure of Semiconductor Single-Wall Carbon Nanotubes. Physics of the Solid State 46: 1168-1172.

9. Hyun CC, Young MJ, Seung BK (2005) size effects in the Raman spectra of $\mathrm{TiO} 2$ nanoparticales Vibration spectroscopy 37: 33-38.

10. Kevin A, Wepasnick, Billy A, Smith, Kaitlin Schrote E, et al. (2001) Surface and structural characterization of multi-walled carbon nanotubes following different oxidative treatments. carbon 49: $24-36$.

11. Papp S, Korosi L, Meynen V, Cool P, Vansant EF, et al. (2005) The influence of temperature on the structural behaviour of sodium tri- and hexa-titanates and their protonated forms. J Solid State Chem 178: 1614-1619.

12. Leroy A, Harold PK (1950) Determination of Crystallite Size with the XRay Spectrometer. J App Phys 21: 137-142.

13. Akhavan O, Azimirad R, Safa S, Larijani MM (2010) Visible light photo-induced antibacterial activity of CNT-doped TiO2 thin films with various CNT continents. J Mater 20: 7386-7392.

14. Quaroni L, Reglinski J, Smith W (1995) Surface enhanced resonance Raman scattering from cyanocobalamin and 5'-deoxyadenosylcobalamin. J Raman Spect 26: 1075-1076.

15. Ohsaka T (1980) Temperature Dependence of the Raman Spectrum in Anatase TiO2. J Phys Jpn 48: 1661.

16. Peng CM, Naveed AS, Gad M, Jang KK (2010) Dispersion and functionalization of carbon nanotubes for polymer-based nanocomposites: A review. Composites Part A 41: 1345-1367. 